\title{
Association of serum adiponectin and visfatin with body composition and selected biochemical cardiometabolic risk factors in non-obese individuals with normal fasting glycaemia
}

\author{
Corresponding author: \\ Katarzyna Bergmann, PhD \\ Department of Laboratory Medicine \\ Nicolaus Copernicus University, \\ Collegium Medicum in Bydgoszcz \\ Skłodowskiej-Curie 9 , \\ 85-799 Bydgoszcz, Poland \\ Tel. +48525854490 \\ fax +48525853603 \\ E-mail: bergmann@vp.p
}

Medical Research Journal 2017; Volume 2, Number 4, 165-171 10.5603/MRJ.2017.0023

Copyright (C) 2017 Via Medica ISSN 2451-2591

\begin{abstract}
Background: Adipose tissue produces many metabolically active substances such as adiponectin and visfatin. Both have potential anti-inflammatory, anti-atherogenic, and increasing insulin sensitivity properties. We evaluated the diagnostic value of serum adiponectin and visfatin as potential cardiometabolic risk factors. Subjects and methods: Sixty non-smoking, non-obese subjects aged 25-40 years with normal fasting glycaemia were included in the study. In all subjects serum fasting lipid profile, CRP, glucose, insulin, and apolipoprotein $\mathrm{Al}$ and $\mathrm{B}$ measurements were performed on an automatic analyser, while adiponectin and visfatin were measured using manual enzyme-linked immunosorbent assay (ELISA). Blood pressure measurements, body composition analysis using bioimpedance method (BIA), and basic anthropometric measurements (weight, BMI, WHR) were performed.

Results: In the study group the concentration of adiponectin and visfatin was significantly inversely and moderately related with the amount of visceral fat, BMI, and waist circumference, while an inverse weak relationship with HOMA-IR and insulin level was observed. Moreover, adiponectin was weakly inversely related with CRP but positively with HDL-C and apolipoprotein Al. The prevalence of subjects with $\mathrm{CRP}<1 \mathrm{mg} / \mathrm{L}$ was significantly higher at the highest adiponectin and visfatin concentrations (third tertile). At the lowest adiponectin concentrations (first tertile) the percentage of subjects with elevated apoB $\geq 100 \mathrm{mg} / \mathrm{dL}$ was increased. Conclusion: The relationship of serum adiponectin and visfatin with the amount of visceral fat, lipid profile, apolipoproteins, and CRP suggests their potential diagnostic value in the assessment of cardiometabolic risk. The predictive value of both adipocytokines should be confirmed in a large population-based study. Key words: adiponectin, visfatin, obesity, metabolic syndrome, cardiometabolic risk
\end{abstract}

Med Res J 2017; 2 (4): 165-171

\section{Introduction}

According to the World Health Organisation, in 2005 around 1.6 billion people worldwide were overweight and more than 522 million were obese. Obesity is not only a medical problem, contributing to about 10$13 \%$ of premature deaths in Europe, but also economic problem. Costs related to the diagnosis and treatment of obesity in Europe range from 2 to $7 \%$ of financial outlays for health care [1]. In recent decades, research on adipose tissue has revealed a number of findings that have allowed adipose tissue to be qualified as an endocrine organ. The discovery of leptin in 1994 was a breakthrough. Since then, many other substances derived from adipose tissue have been isolated, including adipocytokines, various cytokines, and proteins.

Particularly important is the role of adipocytes in the production of adipocytokines and cytokines that regulate systemic inflammation. These indicators are used in routine diagnostics of inflammation and infection. The most important markers of inflammation released from adipose tissue include: TNF- $\alpha$, IL-6, IL- $1 \beta$, and procalcitonin (PCT). Adipocytokines exhibit local and systemic pro- and anti-inflammatory effects. They 
regulate metabolic and systemic processes and play a role in maintaining energy balance in glucose and lipid metabolism. They also participate in immune mechanisms and affect angiogenesis.

Numerous studies have confirmed a strong relationship between type 2 diabetes, metabolic syndrome, and cardiometabolic risk with changes in the level of adipocytokines. Among the most well-known adipocytokines are adipsin, leptin, adiponectin, resistin, and visfatin.

In 2005, the gene for growth factor for early B cells (B-cell colony-enhancing factor, PBEF) was identified in visceral adipose tissue, and the product of this gene was called visfatin. Visfatin (PBEF, NAMPT) is a peptide composed of 491 amino acids [2]. It is produced in adipocytes and macrophages infiltrating adipose tissue and in some cancer cells. Secretion of visfatin fluctuatES throughout the day with the highest concentration observed in the afternoon. Visfatin exerts a hypoglycaemic effect, which is because PBEF directly binds to the insulin receptor at a site other than insulin and promotes glucose uptake in tissues. Visfatin induces the process of differentiation of preadipocytes to adipocytes, and further stimulates the synthesis of proinflammatory cytokines, including IL-6 and IL-8. Its concentration is related to the level of oxidative stress [3].

Adiponectin composed of 244 amino acids constitutes about $0.01 \%$ of all plasma proteins. In women, its concentration is higher than in men [4]. It exhibits structural similarity to collagen type VIII and X, as well as to the complement fraction $\mathrm{C} 1 \mathrm{q}$. In blood, adiponectin occurs in three forms, differing in molecular weight: low molecular weight (trimer) — LMW, medium molecular weight (hexamer) - MMW, and high-molecular weight (built from 12-14 subunits) - HMW.

Adiponectin is derived primarily from adipocytes, but in small amounts from bone marrow cells, endothelial cells of the liver, and cardiomyocytes, and it is metabolised in the kidneys. Adiponectin is involved in many processes: organogenesis, inflammation, glucose metabolism, cell differentiation, and autoimmune reactions [5]. Adiponectin was proven to enhance insulin sensitivity by several mechanisms: increasing the oxidation and transport of free fatty acids, lowering blood glucose by reducing liver gluconeogenesis, inhibition of triglyceride deposition in adipose tissue, and decreasing TNF- $\alpha$ activity in adipose tissue and in macrophages located in the vascular endothelium [6]. Decreased adiponectin levels are observed in obesity, cardiovascular diseases, in subjects with insulin resistance, as well as in in alcoholics and smokers [5].

We evaluated the relationship between serum adiponectin and visfatin concentration with body composition and various biochemical cardiometabolic risk factors in young non-obese normoglycaemic individuals.

\section{Subjects, materials, and methods}

The study consisted of 60 non-obese $\left(\mathrm{BMl}<30 \mathrm{~kg} / \mathrm{m}^{2}\right.$ ), non-smoking, and normoglycaemic (fasting glucose $60-99 \mathrm{mg} / \mathrm{dL}$ ) subjects aged $25-40$ years (30 women, 30 men). Basic anthropometric measurements (body weight, waist circumference, BMI, WHR) and blood pressure measurements with an automatic blood pressure monitor Omron M6 Comfort (Omron Healthcare, Kyoto, Japan) were performed and medical history of chronic diseases was obtained.

Serum and fluoride plasma were collected in the morning (7.00-9.00 a.m.) after 12-hour fast. Samples were centrifuged in low temperature $\left(4^{\circ} \mathrm{C}\right)$. Laboratory tests: glucose, C-reactive protein (CRP), total cholesterol (TC), HDL-cholesterol (HDL-C), triglycerides (TG), and apolipoproteins Al and B (apoAI, apoB) were performed on an Architect ci8200 (Abbott Laboratories, Abbott Park, USA) directly after centrifugation. LDL cholesterol (LDL-C), non-HDL cholesterol (non-HDL-C), and atherogenic index (apoB:apoAl) were calculated. Serum samples were divided into small aliquots for further assays and frozen at $-70^{\circ} \mathrm{C}$ to avoid peptides degradation. Concentration of serum adiponectin and visfatin was assayed using available commercial ELISA kits (Human Adiponectin RD195023100 BioVendor R\&D; Visfatin C-Terminal [Human] EK-003-80, Phoenix Pharmaceuticals, Inc.). Detection limits were $0.26 \mathrm{ng} / \mathrm{mL}$ for adiponectin and $0.1 \mathrm{ng} / \mathrm{mL}$ for visfatin. All laboratory measurements were performed in the Department of Laboratory Medicine, Nicolaus Copernicus University Collegium Medicum in Bydgoszcz, Poland.

Body composition (percentage of body fat, muscle, and visceral fat) was evaluated using a body segment analyser based on electrical bioimpedance (BIA) technology (InnerScan V BC-545N, Tanita). Measurements were performed in the fasting state, in the morning, directly before blood sampling, in accordance with the manufacturer's instructions [7]. The reference values of these parameters depended on age, and for 25-40-year-olds the following values were adopted: fat mass in women $21-33 \%$, in men 8-20\%; level of visceral fat $1-12$; muscle mass in women $>24 \%$, in men $>33 \%$ (according to manufacturer's manual).

Statistical analysis was performed using STATISTICA 12.0 PL software (StatSoft, Inc., 2014). Data were presented as mean \pm standard deviation (normal distribution) or median and $25^{\text {th }}-75^{\text {th }}$ percentile (non-Gaussian distribution). Differences between study groups were measured by t-Student, U-Mann-Whitney, and ANOVA Kruskal-Wallis tests. $P$ values $<0.05$ were considered statistically significant.

The study was approved by the Bioethics Committee at the NCU Collegium Medicum in Bydgoszcz, Poland (No. KB 627/2010) and complied with the World Medical 
Table 1. Clinical characteristics of the study group.

\begin{tabular}{lcccc}
\hline VARIABLES & ALL $(\mathbf{n}=\mathbf{6 0})$ & $\begin{array}{c}\text { WOMEN } \\
(\mathbf{n}=\mathbf{3 0})\end{array}$ & $\begin{array}{c}\text { MEN } \\
(\mathbf{n}=\mathbf{3 0})\end{array}$ & $\begin{array}{c}\text { P } \\
\text { Ws. M }\end{array}$ \\
\hline Age (years) & $30(26-35)$ & $29.5(25-37)$ & $30(27-32)$ & $\mathrm{ns}$ \\
BMI (kg/m2) & $22.7 \pm 2.8$ & $21.3 \pm 2.3$ & $24.1 \pm 2.7$ & $<0.001$ \\
Waist (cm) & $80(69.5-87.5)$ & $70.5(66-76)$ & $87(84-94)$ & $<0.001$ \\
WHR & $0.81(0.75-0.88)$ & $0.75(0.73-0.79)$ & $0.88(0.84-0.89)$ & $<0.001$ \\
SBP (mmHg) & $123 \pm 11$ & $118 \pm 10$ & $129 \pm 10$ & $<0.001$ \\
DBP (mmHg) & $84 \pm 8$ & $81 \pm 9$ & $86 \pm 7$ & 0.036 \\
Fat mass (\%) & $24.4 \pm 6.6$ & $28.2 \pm 5.4$ & $20.6 \pm 5.4$ & $<0.001$ \\
Body mass (\%) & $51 \pm 12.5$ & $40 \pm 3.3$ & $61.9 \pm 7.7$ & $<0.001$ \\
Level of visceral fat & $4.0(2.3-6.0)$ & $2.8(1.5-4.0)$ & $5.75(4.0-8.0)$ & $<0.001$
\end{tabular}

Data presented as mean \pm SD or median (25-75\%)

ns- statistically insignificant $(p>0.05)$

SBP — systolic blood pressure, DBP — diastolic blood pressure

Table 2. Biochemical characteristics of the study group.

\begin{tabular}{|c|c|c|c|c|}
\hline PARAMETER & ALL $(n=60)$ & $\begin{array}{l}\text { WOMEN } \\
(\mathrm{n}=30)\end{array}$ & $\begin{array}{c}\text { MEN } \\
(n=30)\end{array}$ & $\begin{array}{c}P \\
\text { W vs } M\end{array}$ \\
\hline Glucose (mg/dL) & $92(88-96)$ & $89(85-93)$ & $96(92-99)$ & $<0,001$ \\
\hline $\mathrm{CRP}(\mathrm{mg} / \mathrm{L})$ & $0.5(0.35-1.1)$ & $0.5(0.4-1.1)$ & $0.6(0.3-1.2)$ & ns \\
\hline Insulin $(\mu \mathrm{U} / \mathrm{mL})$ & $6.6(5.1-9.0)$ & $5.95(5.24-7.36)$ & $7.9(5.0-10.4)$ & 0.036 \\
\hline HOMA-IR & $1.5(1.1-2.1)$ & $1.32(1.1-1.6)$ & $1.86(1.2-2.4)$ & 0.012 \\
\hline $\mathrm{TC}(\mathrm{mg} / \mathrm{dL})$ & $189.6 \pm 35.8$ & $186 \pm 34$ & $193 \pm 38$ & ns \\
\hline HDL-C (mg/dL) & $55 \pm 12$ & $61 \pm 11$ & $48 \pm 8$ & $<0.001$ \\
\hline $\mathrm{TG}(\mathrm{mg} / \mathrm{dL})$ & $82(65-109)$ & $74(64-88)$ & $99(67-127)$ & 0.014 \\
\hline LDL-C (mg/dL) & $117 \pm 32$ & $109 \pm 29$ & $124 \pm 33$ & ns \\
\hline non- HDL-C (mg/dL) & $135 \pm 36$ & $125 \pm 30$ & $145 \pm 39$ & 0.028 \\
\hline apoAl (mg/dL) & $145 \pm 23$ & $158 \pm 21$ & $133 \pm 17$ & $<0.001$ \\
\hline apoB (mg/dL) & $78.0 \pm 21$ & $74 \pm 16$ & $82.8 \pm 22.7$ & ns \\
\hline apoB:apoAl & $0.56 \pm 0.19$ & $0.47 \pm 0.12$ & $0.64 \pm 0.21$ & $<0.001$ \\
\hline Adiponectin (ng/mL) & $10(8-17)$ & $11(9-17)$ & $8.9(6.7-16.6)$ & ns \\
\hline Visfatin (ng/mL) & $13(8.3-22)$ & $15.2(8.7-26.6)$ & $12(8.3-19.7)$ & ns \\
\hline
\end{tabular}

Data presented as mean \pm SD or median $(25-75 \%)$

ns- statistically insignificant $(p>0.05)$

Association Declaration of Helsinki regarding ethical conduct of research involving human subjects. From all participants involved in this study informed written consent was collected.

\section{Results}

Clinical and biochemical characteristics of the study group were presented in Tables 1 and 2. All variables showed statistically significant gender differences. In women significantly higher percentage of fat mass, HDL-cholesterol, and apoAl concentrations were found. In men higher values of BMI, WHR, waist circumference, blood pressure, and almost twofold higher level of visceral fat were observed. In addition men showed significantly higher fasting glucose, insulin, HOMA-IR, triglycerides, non-HDL-C, and apoB:apoAI. Serum adiponectin and visfatin concentrations varied at 4.4-29.3 $\mathrm{ng} / \mathrm{mL}$ and $1.9-36.3 \mathrm{ng} / \mathrm{mL}$, respectively. Median adiponectin and visfatin concentrations were only slightly higher in women compared to men.

Correlation analysis performed in the whole study group showed a significant moderate inverse relation- 
Table 3. Correlation of adiponectin and visfatin with selected variables (R-coefficient values; grey fields — results statistically significant $p<0.05)$

\begin{tabular}{|c|c|c|c|c|c|c|}
\hline \multirow[t]{2}{*}{ Variables } & \multicolumn{2}{|c|}{ All $(n=60)$} & \multicolumn{2}{|c|}{ Women $(n=30)$} & \multicolumn{2}{|c|}{ Men $(n=30)$} \\
\hline & Adiponectin & Visfatin & Adiponectin & Visfatin & Adiponectin & Visfatin \\
\hline BMI & -0.46 & -0.33 & -0.35 & -0.32 & -0.50 & -0.37 \\
\hline Waist & -0.43 & -0.30 & -0.46 & -0.36 & -0.48 & -0.41 \\
\hline WHR & -0.32 & -0.19 & -0.22 & -0.25 & -0.37 & -0.20 \\
\hline CRP & -0.30 & -0.23 & -0.46 & -0.21 & -0.17 & -0.24 \\
\hline Insulin & -0.34 & -0.34 & -0.20 & -0.28 & -0.36 & -0.39 \\
\hline HOMA-IR & -0.38 & -0.34 & -0.24 & -0.31 & -0.41 & -0.37 \\
\hline $\mathrm{TC}$ & -0.13 & 0.05 & 0.30 & 0.32 & -0.43 & -0.21 \\
\hline LDL-C & -0.19 & 0.01 & 0.22 & 0.31 & -0.44 & -0.24 \\
\hline HDL-C & 0.34 & 0.18 & 0.33 & 0.16 & 0.26 & 0.21 \\
\hline non-HDL-C & -0.22 & -0.01 & 0.22 & 0.31 & -0.46 & -0.26 \\
\hline apoAl & 0.27 & 0.13 & 0.29 & 0.07 & 0.14 & 0.18 \\
\hline Fat mass \% & -0.48 & -0.38 & -0.61 & -0.33 & -0.78 & -0.65 \\
\hline Visceral fat & -0.68 & -0.41 & -0.64 & -0.42 & -0.77 & -0.47 \\
\hline
\end{tabular}

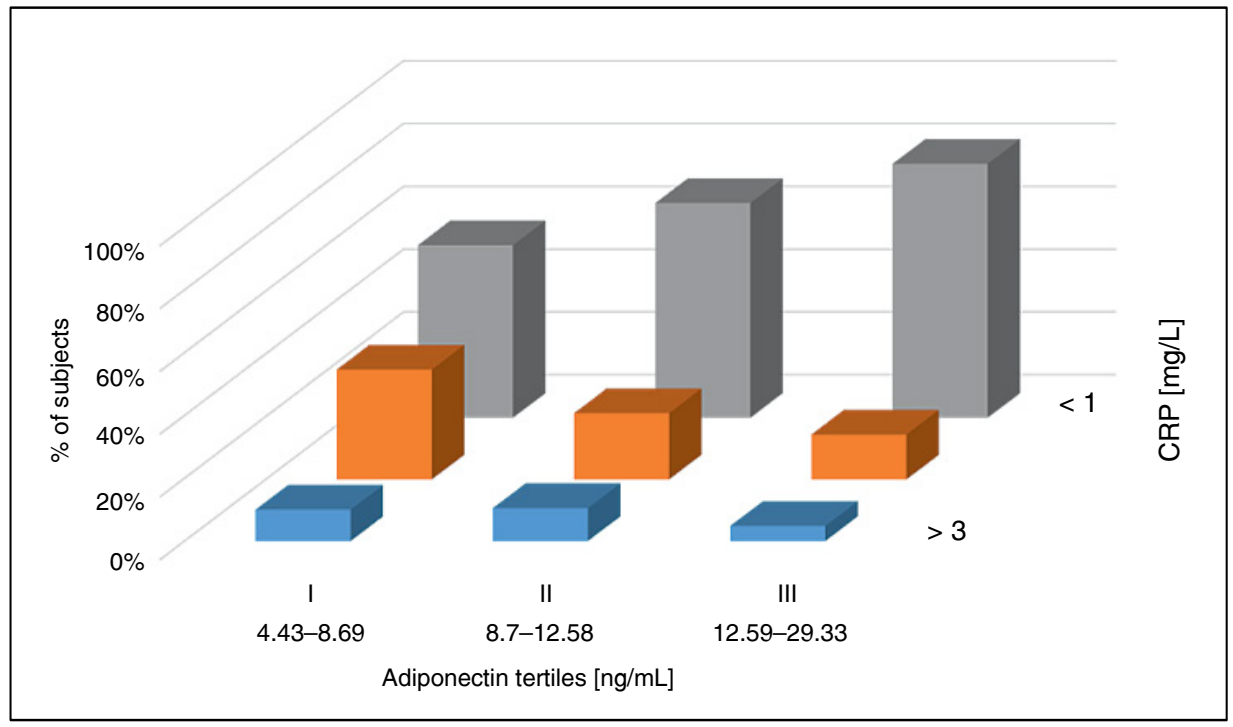

Figure 1. Prevalence of subjects in the groups determined by the values of adiponectin and CRP.

ship of adiponectin and visfatin with the percentage of fat mass, visceral fat, BMI, and waist circumference, whereas the inverse correlation with HOMA-IR and insulin was weak (Table 3).

Adiponectin was weakly inversely related to WHR and CRP $(R=-0.30 ; p=0.022)$, but a positive correlation was observed with HDL-C $(R=0.34 ; p=0.009)$ and apoAI $(R=0.27 ; p=0.002)$.

Visfatin, similarly to adiponectin, showed a weak negative correlation with BMI, waist circumference, HOMA-IR, and body composition parameters: percentage fat mass $(R=-0.38 ; p=0.003)$ and visceral fat $(R=-0.41 ; p=0.001)$.
In men a stronger relationship of adiponectin and visfatin with anthropometric parameters, percentage fat mass, and visceral fat was found compared to women. Similarly, in men a significant, weak, negative correlation was observed between both adipocytokines and HOMA-IR and insulin. Only in men did select lipid parameters correlate significantly with adiponectin: $\mathrm{TC}(\mathrm{R}=-0.43 ; \mathrm{p}=0.017)$, LDL-C $(R=-0.44 ; p=0.015)$ and non-HDL-C $(R=-0.46 ; p=0.011)$.

Interestingly, a significant correlation of adiponectin with CRP was found only in women $(R=-0.46 ; p=0.01)$.

In further analysis, subjects were divided into three groups according to tertiles of adiponectin and visfatin 


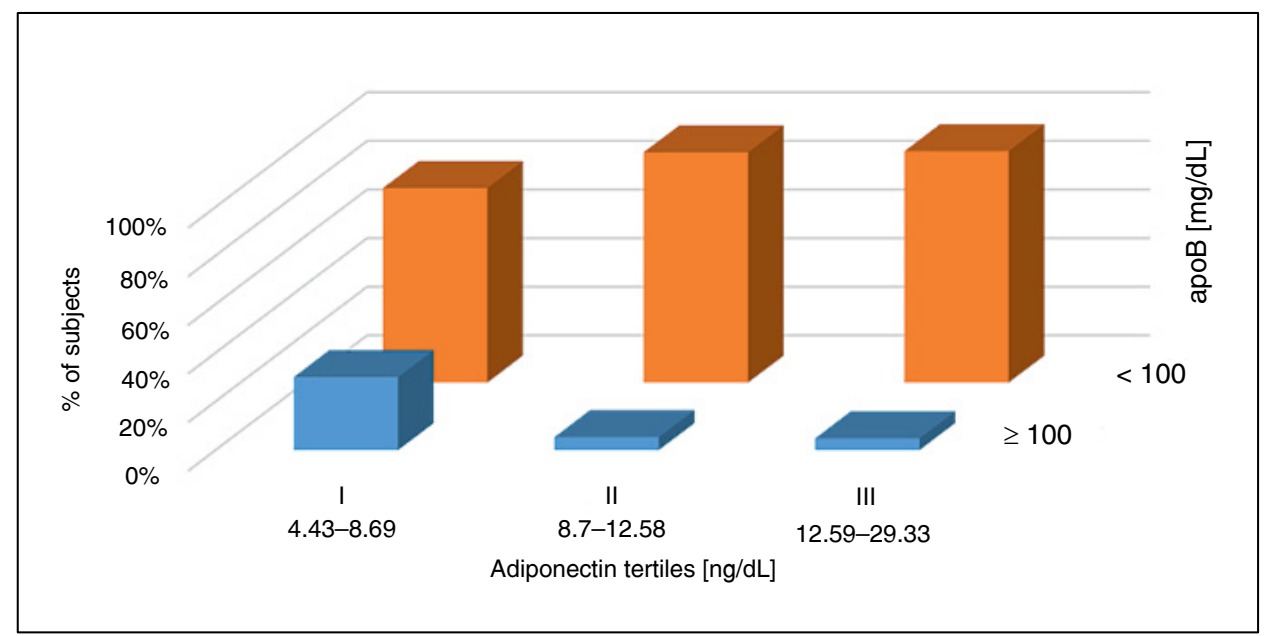

Figure 2. Prevalence of subjects in the groups determined by the values of adiponectin and apoB.

concentrations. For adiponectin, the concentration ranges were: 4.43-8.69 (first tertile), 8.70-12.58 (second tertile), and 12.59-29.33 (third tertile) $\mathrm{ng} / \mathrm{mL}$. For visfatin, the distribution in tertiles was as follows: 1.86-9.58 (first tertile), 9.59-18.86 (second tertile), and 18.87-36.29 (third tertile) $\mathrm{ng} / \mathrm{mL}$. In subsequent adiponectin tertiles, a significant decrease in values of BMI $(p=0.02)$, waist circumference $(p=0.002)$, level of visceral fat $(p<0.001)$, and insulin concentration $(p=0.018)$ were observed (data not presented). For visfatin, similar trends were found only with the level of visceral fat $(p<0.01)$ and triglycerides $(p=0.03)$.

With the increase in adiponectin concentration the number of subjects with low CRP $<1 \mathrm{mg} / \mathrm{L}$ significantly rose $(p<0.05$; Figure 1 ). An analogous relationship was observed for visfatin (data not presented). Moreover, the highest number of subjects with elevated apoB $\geq 100 \mathrm{mg} / \mathrm{dL}$ was found at the lowest adiponectin concentrations (Figure 2).

\section{Discussion}

The analysis of body composition, especially the level of visceral fat, and laboratory markers of chronic inflammation, for example adipocytokines, may be useful for a more complete assessment of the risk of insulin resistance and cardiovascular diseases [8-9]. Despite the fact that the problems of obesity and metabolic syndrome have been discussed for years, the determination of adiponectin, visfatin, and body composition are still relatively rarely used in clinical practice to assess cardiometabolic risk.

In this study, no significant differences in adiponectin and visfatin concentrations were found for women and men; however, median concentrations were slightly higher in women. Cnop et al. observed significantly higher adiponectin concentrations in women compared to men (7.4 \pm 2.9 vs. $5.4 \pm 2.3 \mathrm{ng} / \mathrm{mL} ; \mathrm{p}<0.001)$ [10]. This phenomenon is explained by a higher percentage of adipose tissue in the females.

Yamamoto et al. showed a significant relationship between adiponectin levels and the value of arterial pressure, while Patel et al. did not observe such a correlation [11-12]. Yamamoto et al., in a group of 967 subjects aged 30-65 years, also found negative correlation of adiponectin concentration with BMI, insulin concentration, TC, TG, LDL-C, and insulin resistance index HOMA-IR and a positive correlation with HDL cholesterol level [ 11].

In several studies on obese subject with metabolic syndrome a negative correlation was found between adiponectin concentration and waist circumference [13-14], as well as with insulin resistance [15]. Interestingly, an inverse correlation between adiponectin and CRP was observed in a group of 312 men over 50 years of age [16], whereas in our study such a correlation was observed only in women. Our observation is based on the results from a small group of men, which is a limitation of this study and could influence the correlation analysis.

Adiponectin concentrations were related most of all with the indices of body fat composition, which indicates the important role of low concentrations of adiponectin in the pathogenesis of obesity, as well as its subsequent cardiometabolic complications.

The importance of visfatin in the pathogenesis of obesity and metabolic syndrome has not been clearly defined so far, and some other studies have yielded conflicting results. Fukuhara et al. showed significant correlation between visfatin concentration and the level of visceral fat and percentage of adipose tissue [17], whereas in a study by Berndt et al. no significant relationship was found between visfatin concentration and adipose tissue, as well as with insulin and BMI 
[18]. Others showed a correlation between visfatin concentration with waist circumference and diastolic blood pressure and no significant dependence on BMI, HDL-C, and triglycerides [19]. In our study, moderate and weak negative correlations were observed between visfatin concentration and $\mathrm{BMI}$, waist circumference, HOMA-IR, and, similarly to adiponectin, fat mass and level of visceral fat.

Controversial data in recent years indicate the potential role of visfatin in the pathogenesis of atherosclerosis and cardiovascular disease. They show that ox-LDL cause an increase in the expression of visfatin in cultured monocytes. Its high expression is also exhibited by macrophages in unstable atherosclerotic plaques; hence, visfatin may play a role in the destabilisation of atherosclerotic plaque. Its elevated concentrations are observed in groups of patients with unstable coronary disease (compared to stable disease) and after ischaemic stroke [20]. A study by Lim et al. conducted on mice showed that after the ischaemic event bolus administration of high concentration of visfatin reduced the size of the infarction [21]. Therefore, it seems that the increase in blood visfatin concentration in atherosclerosis and cardiovascular complications may be the result of a compensation mechanism associated with the induction of inflammation and vascular damage.

Based on the analysis of prospective population-based studies, it was clearly stated that hypoadiponectinaemia is a significant risk factor for cardiovascular disease and metabolic syndrome. In a study of 577 patients aged $25-74$ years, a significant association of low adiponectin concentration on cardiovascular disease was observed, resulting in a negative effect on the metabolism of fatty acids directly involved in the development of hypertension [22]. Kumada et al. found significantly lower adiponectin level in a group of 225 men aged 40-69 years after coronarography, compared to the control group $(4.7 \mathrm{ng} / \mathrm{mL}$ vs. $5.9 \mathrm{ng} / \mathrm{mL}$, $p<0.001$ ), which proves that hypoadiponectinaemia was significantly and independently associated with the onset of ischaemic heart disease (IHD; $p<0.008$ ) [23]. In this study, subjects were divided according to quartiles of adiponectin concentrations. In the first quartile $(<4 \mathrm{ng} / \mathrm{mL})$, the risk of IHD was more than 2.5 -fold higher than in the fourth quartile $(>7 \mathrm{ng} / \mathrm{mL}$ ), regardless of other risk factors (OR $=2.051 ; \mathrm{Cl} 95 \%$ $1.288-4.951$ vs. $\mathrm{OR}=0.749 ; 95 \% \mathrm{Cl} 0.392-1.418)$. Mohan et al. showed that adiponectin levels were significantly lower in patients with MetS compared to the control group (men: 5.0 vs. $6.8 \mathrm{ng} / \mathrm{mL} ; \mathrm{p}=0.01$; women: 6.5 vs. $9.9 \mathrm{ng} / \mathrm{mL} ; \mathrm{p}=0.001$ ). The analysis of the relationship showed a strong negative relationship between the concentration of adiponectin and the prob- ability of the onset of metabolic syndrome in the study group ( $p<0.001$ ) [24]. In our study, the highest prevalence of subject with $\mathrm{CRP}<1 \mathrm{mg} / \mathrm{L}$, which reflects low relative risk of cardiovascular disease, was observed in the third adiponectin tertile, while an increased number of subjects with elevated $a p o B \geq 100 \mathrm{mg} / \mathrm{dL}$ was found in the first tertile. This might indicate that in apparently healthy, non-obese individuals low adiponectin levels are associated with low-grade inflammation and dyslipidaemia, which increases cardiometabolic risk.

Considering the results of our own study and the presented relationships between adiponectin and visfatin concentration with select parameters of body composition, as well as biochemical risk factors for metabolic syndrome and cardiovascular diseases, it seems that the determination of these adipocytokines may be clinically useful in the more accurate assessment of possible cardiometabolic disorders in young, healthy people. However, due to the limitation of the study (small study group) the predictive value of both adipocytokines should be confirmed in a large population-based study.

Authors' conflict of interest disclosure: The authors state that there are no conflicts of interest regarding the publication of this article.

\section{List of abbreviations}

apoAI - apolipoprotein Al

apoB - apolipoprotein B

$\mathrm{BIA}$ - bioelectrical impedance analysis

$\mathrm{BMI}$ - body mass index

CRP - C-reactive protein

DBP — diastolic blood pressure

ELISA - enzyme-linked immunosorbent assay

HOMA-IR - homeostatic model assessment-insulin resistance

HDL-C - high-density lipoprotein cholesterol

IHD - ischaemic heart disease

IL-6 - interleukin 6

$\mathrm{IL}-1 \beta$ - interleukin $1 \beta$

LDL-C - low-density lipoprotein cholesterol

non-HDL-C - non-high-density lipoprotein cholesterol

PBEF / NAMPT - B-cell colony-enhancing factor, visfatin

$\mathrm{PCT}$ - procalcitonin

SBP — systolic blood pressure

TC - total cholesterol

$\mathrm{TG}$ - triglycerides

TNF- $\alpha$ - tumor necrosis factor $\alpha$

WHR - waist-to-hip ratio 


\section{References}

1. 1.World Health Organization. The challenge of obesity in the WHO European Region. Fact sheet EURO. 2005; 13: 1-4

2. Zhang LiQ, Heruth DP, Ye SQ. Nicotinamide Phosphoribosyltransferase in Human Diseases. J Bioanal Biomed. 2011; 3: 13-25, doi: 10.4172/1948-593X.1000038, indexed in Pubmed: 22140607.

3. jr VT, Senolt L, Hulejova $H$, et al. Early changes in serum visfatin after abdominal surgery: a new pro-inflammatory marker in diagnosis? Biomedical Papers. 2014, doi: 10.5507/bp.2014.012.

4. Arita Y, Kihara S, Ouchi N, et al. Paradoxical decrease of an adipose-specific protein, adiponectin, in obesity. Biochem Biophys Res Commun. 1999; 257(1): 79-83, indexed in Pubmed: 10092513

5. Olszok J, Wyganowska A, Tarabura-Dragon J, et al. Selected adipocytokines and their potential role in the control of the course of chronic hepatitis B and C. Annales Academiae Medicae Silesiensis. 2015; 69: 1-7, doi: 10.18794/aams/23858

6. Dabrowska M, Szydlarska D, Bar-Andziak E. Adiponektyna a insulinooporność i miażdżyca. Endokrynologia, Otyłość i Zaburzenia Przemiany Materii. 2011; 7(3): 186-189.

7. Tanita ${ }^{\circledR}$ official website Available at: https://www tanita com/en/ [cited: 01 03. https://www.tanita.com/en/ [cited: 01.03.2018].

8. Musialik K. Wybrane wykładniki stanu zapalnego u pacjentów z zespołem metabolicznym. Przegląd Kardiodiabetologiczny. 2012; 7: 31.

9. Albu A, Delia L. Adipokines, systemic inflammation and exercise; Palestrica of the third millennium. Civilization and Sport. 2015; 16(3): 257-261.

10. Cnop M Havel PJ Utzschneider KM et al. Relationship of adiponectin to body fat distribution, insulin sensitivity and plasma lipoproteins: evidence for independent roles of age and sex. Diabetologia. 2003; 46(4): 459-469, doi: 10.1007/s00125-003-1074-z, indexed in Pubmed 12687327

11. Yamamoto $\mathrm{Y}$, Hirose $\mathrm{H}$, Saito I, et al. Correlation of the adipocyte-derived protein adiponectin with insulin resistance index and serum high-density lipoprotein-cholesterol, independent of body mass index, in the Japanese population. Clin Sci (Lond). 2002; 103(2): 137-142, doi: 10.1042/, indexed in Pubmed: 12149104.

12. Patel JV, Lim HS, Hughes EA, et al. Adiponectin and hypertension: a putative link between adipocyte function and atherosclerotic risk? J Hum Hypertens. 2007; 21(1): 1-4, doi: 10.1038/sj.jhh.1002078, indexed in Pubmed: 16871286.
13. Bogdański P, Iciek J. Musialik- Pupek D. Wpływ regularnej aktywności fizycznej na stężenie adiponektyny u otyłych kobiet z zespołem metabolicznym. Endokrynologia, Otyłość i Zaburzenia Przemiany Materii 2011; 7(4): 213.

14. Foremska- Ic, Kubacka E. Łuczak- Kujawska M, Musialik- Pupek D. Ocena stężenia adiponektyny u pacjentów z otyłością prostą. Forum Zaburzeń Metabolicznych. 2013; 4(1): 43-48.

15. Kadowaki T. Adiponectin and adiponectin receptors in insulin resistance, diabetes, and the metabolic syndrome. Journal of Clinical Investigation. 2006; 116(7): 1784-1792, doi: 10.1172/jci29126.

16. Paschalis-Purtak K, Puciłowska B Janas J et al Adiponectin and leptin plasma concentrations in men with coronary artery disease with and without hypertension. Nadciśnienie Tętnicze. 2009; 13(2): 74-81.

17. Fukuhara A, Matsuda M, Nishizawa M, et al. Visfatin: a protein secreted by visceral fat that mimics the effects of insulin. Science. 2005; 307(5708): 426-430, doi: 10.1126/science.1097243, indexed in Pubmed: 15604363.

18. Böttcher $Y$, Teupser D, Enigk B et al. Plasma visfatin concentrations and fat depot-specific mRNA expression in humans. Diabetes. 2005; 54(10): 2911-2916, indexed in Pubmed: 16186392

19. Foremska- Ic, Hoffmann K. Musialik- Pupek D. Ocena osoczowego stężenia wisfatyny u chorych z zespołem metabolicznym i samoistnym nadciśnieniem tętniczym. Nadciśnienie tętnicze. 2009; 13(4): 258-262.

20. Saddi-Rosa P, Oliveira CSV, Giuffrida FMA, et al. Visfatin, glucose metabolism and vascular disease: a review of evidence. Diabetol Metab Syndr 2010; 2: 21, doi: 10.1186/1758-5996-2-21, indexed in Pubmed: 20346149.

21. Lim SY, Davidson SM, Paramanathan AJ, et al. The novel adipocytokine visfatin exerts direct cardioprotective effects. J Cell Mol Med. 2008; 12(4): 1395-1403, doi: 10.1111/j.1582-4934.2008.00332.x, indexed in Pubmed: 18400051.

22. Hui $E, X u A$, Chow WS, et al. Hypoadiponectinemia as a predictor for the development of hypertension: a 5-year prospective study. Hypertension. 2007; 49(6): 1455-1461, doi: 10.1161/HYPERTENSIONAHA.107.086835, indexed in Pubmed: 17452504.

23. Kumada M, Kihara S, Sumitsuji S, et al. Osaka CAD Study Group. Coronary artery disease. Association of hypoadiponectinemia with coronary artery disease in men. Arterioscler Thromb Vasc Biol. 2003; 23(1): 85-89, indexed in Pubmed: 12524229.

24. Mohan V, Deepa R, Pradeepa R, et al. Association of low adiponectin levels with the metabolic syndrome--the Chennai Urban Rura Epidemiology Study (CURES-4). Metabolism. 2005; 54(4): 476-481, doi: 10.1016/..metabol.2004.10.016, indexed in Pubmed: 15798954. 